\title{
ARGILA DISPERSA EM ÁGUA E GRAU DE FLOCULAÇÃO EM CLASSES DE SOLOS
}

\section{CLAWLESS SCAFFOLD IN WATER AND FLOCCULATION DEGREE IN SOIL CLASSES}

Jeane Cruz Portela ${ }^{1}$; Antônio Carlos da Silva ${ }^{2}$; Safira Yara Azevedo Medeiros da Silva ${ }^{3}$; Max Andrez de Souza Oliveira ${ }^{4}$; Francisco Wellington Andrade Silva ${ }^{5}$

DOI: https://doi.org/10.31692/978-65-991061-7-0.294-299

\section{INTRODUÇÃO}

A argila dispersa em água refere-se à porção de argila total naturalmente dispersa sob ação da água, enquanto o grau de floculação corresponde à percentagem de argilas floculadas, sendo estas duas variáveis inversamente proporcionais e comumente utilizadas como índices para avaliar a estabilidade estrutural do solo e consequentemente sua susceptibilidade ao processo erosivo (MOTA et al., 2013, VAN LIER, 2010)

O fenômeno da dispersão/floculação dos colóides do solo está associado ao balanceamento entre as cargas negativas e positivas, sendo influenciada pela textura, mineralogia, $\mathrm{pH}$ e sais solúveis. A dispersão é favorecida pela predominância de cargas negativas, enquanto que o balanceamento de cargas negativas e positivas, propicia a aproximação entre os coloides de argila, culminando no processo de floculação e formação dos micro agregados, sendo um fenômeno importante do ponto de vista pedogenético e estrutural do solo (BORDAM , 2010).

Diante do exposto, o objetivo do presente trabalho foi avaliar a argila dispersa em água, assim como o grau de floculação em classes de solos, no assentamento rural Terra de Esperança, município de Governador Dix- Sept Rosado RN.

\section{FUNDAMENTAÇÃO TEÓRICA}

O entendimento dos fenômenos de dispersão/ floculação do solo, por meio do uso de indicadores de estabilidade estrutural são de fundamental importância do ponto de vista agrícola para o controle da erosão e consequentemente manutenção da estabilidade estrutural do solo, condição ideal para crescimento vegetal (TAVARES FILHO et al., 2010).

Nesse sentido, as análises de a argila dispersa em água (ADA) e grau de floculação (GF) têm sido amplamente utilizadas na avaliação de condições estruturais do solo, tendo em vista que quanto maior os valores de ADA, menor será a estabilidade de agregados e a resistência do solo aos processamentos de degradação, enquanto que maiores valores de GF 
são indicativo de estabilidade estrutural, por refletir na união entre as partículas e consequentemente resistência à ação dos agentes erosivos, tornam-se importantes para estudos de conservação do solo (FREITAS, 2011; DONTSOVA et al., 2009).

\section{METODOLOGIA}

A pesquisa foi realizada no Projeto de Assentamento Terra da Esperança, em Governador Dix-Sept Rosado, Rio Grande do Norte. Foram selecionados quatro classes de solo,: Latossolo Vermelho-amarelo; Chernossolo Rêndzico; Cambissolo Háplico e Neossolo Flúvico .

Coletaram-se amostras deformadas nos respectivos horizontes das classes em estudo, sendo acondicionadas em sacos plásticos e posteriormente levadas ao Laboratório de Análises de Solo, Água e Planta do Centro de Ciências Agrárias da Universidade Federal Rural do Semiárido (LASAP-CCA-UFERSA).

As amostras foram secas ao ar, destorroadas e passadas em peneira, com malha de 2 mm de abertura, para obtenção da terra fina seca ao ar (TFSA) e, posteriormente submetidas as análises físicas de granulometria, argila dispersa em hexa e em água, sendo posteriormente calculada o grau de floculação $(\mathrm{GF} \%)$ e a relação silte/argila. A análise granulométrica, conforme foi realizada pelo método da pipeta, conforme Teixeira et al., ( 2017), onde a fração areia $(2-0,05 \mathrm{~mm})$ foi obtida por tamisagem, a argila $(<0,002 \mathrm{~mm})$ por sedimentação e o silte $(0,05-0,002)$ por diferenciação.

Argila dispersa em água (ADA) foi determinada a partir da TFSA, utilizando-se agitação mecânica lenta (tipo Wagner $50 \mathrm{rpm}$ por 16 horas) e água destilada. O grau de floculação (GF\%) da argila foi calculado pela expressão seguindo a metodologia descrita no manual de métodos de análises físicas (TEIXEIRA et al., 2017), sedo expressa conforme equação descrita abaixo, enquanto a relação Silte/Argila constitui de uma razão simples entre os teores de silte e argila.

$$
\begin{aligned}
& \mathrm{GF}=100 *(\text { Argila em Hexa }- \text { Argila em Água }) \\
& \text { Argila em Hexa }
\end{aligned}
$$

Os resultados dos atributos do solo foram expressos na média de quatro repetições (laboratório) por horizonte nas classes em estudo.

\section{RESULTADOS E DISCUSSÕES}


Na Tabela 1, encontra-se representado a distribuição do tamanho das partículas, sua classificação textural, argila em hexa e em água, relação silte/argila e grau de floculação em classes de solos, nos respectivos horizontes.

Tabela 1. Distribuição do tamanho das partículas, sua classificação textural, argila em Hexa e em água, relação silte/argila e o grau de floculação em classes de solos, nos respectivos horizontes, no Projeto de Assentamento

Terra de Esperança-RN. Fonte: própria

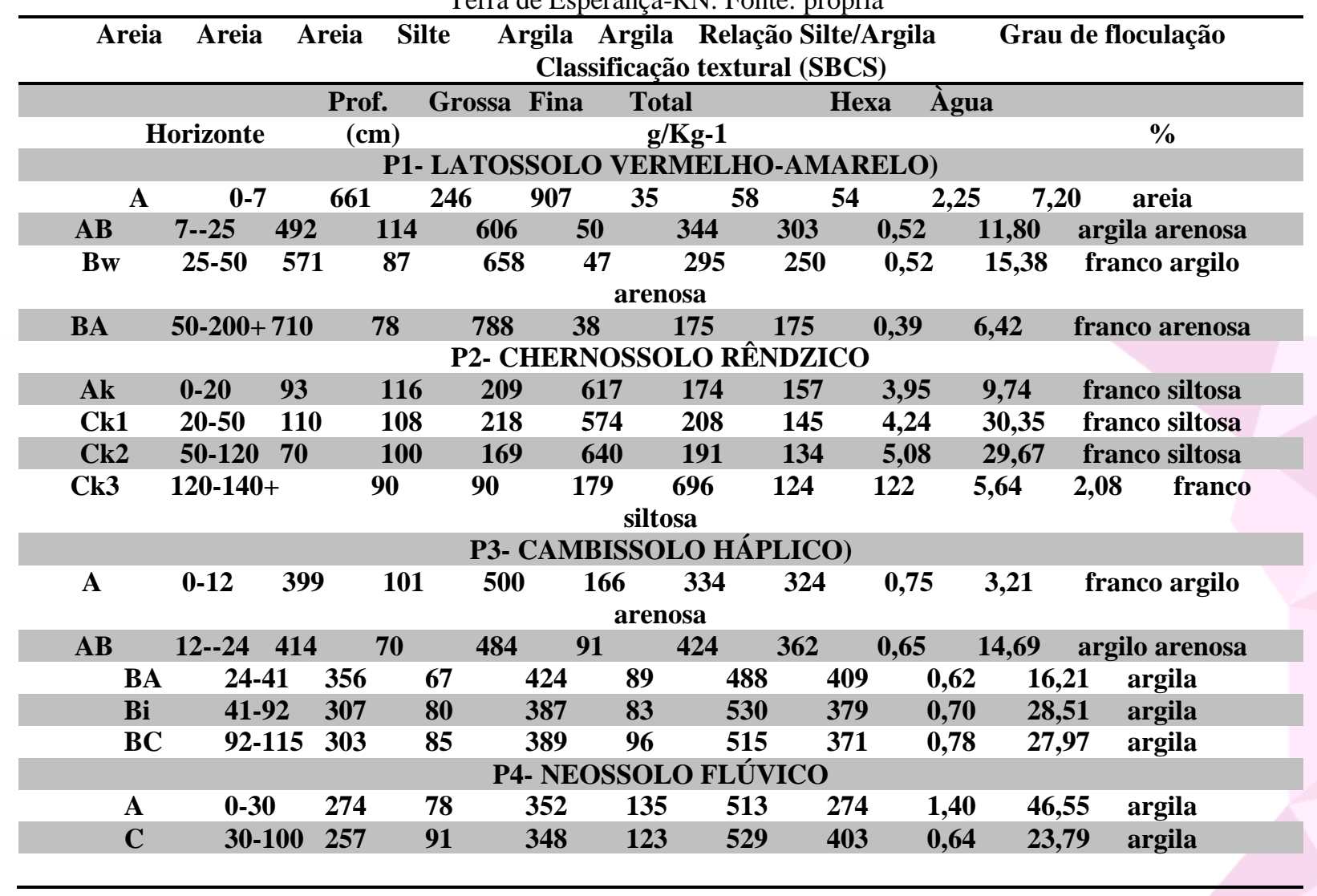

Para a análise granulométrica, os perfis apresentaram variações texturais, prevalecendo à classificação franca arenosa (Latossolos Vermelho-amarelo); franco siltosa (Chernossolo Rêndzico), Franco argilo arenosa (Cambissolo Háplico), e argila (Neossolos Flúvicos). Observa-se que os maiores teores de argila foram conferidos a classe dos Cambissolos Háplicos, variando de 219 a 530 g kg-1 e Neossolos Flúvicos (513 a 529 g kg1). A fração silte foi expressiva para distinguir a classe do Chernossolo Rêndzico, com valores variando de 574 a 696 g kg-1, obtendo classificação textural Franco siltosa (Tabela 1).

Com relação aos valores de argila dispersa em água (ADA), e grau de floculação (GF) nota-se que na classe de Latossolo, os menores valores de ADA e GF encontram-se na superfície, (horizonte A, com 54 g kg-1 e 7,20\% respectivamente), ocorrendo, contudo, incremento nestes dois atributos conforme aumento da profundidade nos horizontes $\mathrm{AB}, \mathrm{Bw}$ e BA (tabela 1). Nesse sentido, os valores de ADA e GF são inversamente proporcionais e estão 
associados ao tipo e teor de argila nos diferentes horizontes do Latossolos, uma vez que a textura está entre os principais fatores de influência do grau de floculação/dispersão das (RODRIGUES et al., 2011, EFFGEN et al., 2006).

A predominância da fração areia no Latossolo em superfície, em detrimento da fração argila, contribui para os menores valores de GF, uma vez que a fração areia é inerte, não apresentando cargas negativas nem atividade coloidal, ao contrário da fração argila, que é a fração ativa do solo, atuando por meio do balanceamento das cargas negativas, aproximando os colóides e favorecendo a floculação, unificando as partículas minerais (CZYS \& DEXTER, 2015). Além disso, os Latossolos, por serem solos muito intemperizados, apresentam pH ácido, com predominância de e argilas de mineralogia 1:1, gerando cargas elétricas positivas dos óxidos de ferro e alumínio, que bloqueiam fortemente as cargas negativas da caulinita, favorecendo o balanceamento das cargas negativas, e consequentemente permitindo a floculação dos colóides, gerando os microagregados, razão pela qual os Latossolos são porosos e bem drenados, sobretudo no horizonte diagnóstico Bw (SANTOS et al., 2018).

Quanto ao Chernossolo, verifica-se tendência semelhante à do Latossolo, com resultados maiores de ADA e GF nos horizontes Ck1 (145g kg-1 e 30, 35\% respectivamente) e Ck2 (191 e 29,67 \% respectivamente). Vale ressaltar no Chernossolo os elevados teores da fração silte (variando de 574 a 696 g kg-1), foram determinantes para lhe conferir classificação textural franco siltosa em todos os horizontes, como também da relação Silte/Argila $(3,95$ a 5,64), indicativo de solos jovens, pouco inteperizados e com restrições a drenagem de água. Melo et al. (2017), estudando diferentes ordens de Chernossolo na Chapada do Apodi-RN, encontraram condições semelhantes e, atribuíram ao calcário fossilífero (material de origem) de granulação fina.

Nesse sentido, é possível concluir que o Chernossolo Rêndzico, apesar de apresentar maiores valores de GF comparativamente ao Latossolo, torna-se mais susceptível ao processo erosivo do que este em função da predominância da fração silte em detrimento da fração argila, refletindo nos valores de GF. Na fração silte, as partículas são pequenas, sem atividade coloidal, apresentando consequentemente pegajosidade, sem plasticidade, o que torna os solos siltosos mais suscetíveis à desagregação e ao carreamento das partículas pelo processo erosivo pela ação dos agentes erosivos água e vento (DYONÍSIO, 2010).

Em relação ao Cambissolo Háplico e ao Neossolo Flúvico, estes apresentaram de forma geral, maiores valores de ADA e GF, aumentando em profundidade no caso de Cambisolo hpalico, contudo os maiores valores no Neossolo Flúvico (tabela 1). Isso pode ser 
explicado em função da textura, uma vez que nestas duas classes verificaram-se os mais altos teores de argila, com destaque para o Neossolo Flúvico (513 a 529 g kg-1), com classificação textural argilosa, refletindo nos valores de ADA e maior GF.

Tal fato é incomum para essa ordem de solos, podendo ser explicado em função da posição na paisagem (área coluvial), onde normalmente áreas de baixas cotas recebem sedimentos oriundos de outros locais, dos quais a fração argila, por ser mais leve, é mais facilmente transportada e depositada nas áreas aluviais, bem como a influência do lençol freático.

\section{CONCLUSÕES}

O Latossolo apresentou os menores valores de ADA e GF na superfície associados à predominância da fração areia ocorrendo, contudo, incremento nestes dois atributos em profundidade, com incremento da fração argila.

O Chernossolo Rêndzico apresentou a maior relação silte/argila, como também maiores teores de silte, e maiores valores de ADA e GF, contudo maior susceptibilidade ao processo erosivo devido textura siltosa.

Tanto no Cambissolo Háplico quanto no Neossolo Flúvico, houve predominância da fração argila, refletindo nos valores de ADA e GF em ambas as classes.

\section{REFERÊNCIAS}

BOARDMAN J. A short history of muddy floods. L Degrad Dev. 2010;21:303 - 309.

CZYŻ, E. A.; DEXTER, A. R. Mechanical dispersion of clay from soil into water: readilydispersed and spontaneously-dispersed clay. International Agrophysics, v. 29, n. 1, p. 31-37, 2015.

DANTSOVA, K.M; HAYES, C .; PENNINGTON, J.C \& PORTER , B. Sorpion of high explosives to water-dispersible clay: influence of organic carbon, aluminosilicate clay, and extractable iron. Journal of environmental quality, v. 38, n. 4, p. 1458-1465, 2009.

DE FREITAS, R. D. C. A. Argila dispersa em água determinada por agitação rápida, lenta e ultrassom. 2011. Tese de Doutorado. Universidade Federal de Viçosa.

DIONISIO, H. A, F. Erosão hídrica: Suscetibilidade do solo. Revista Eletrônica Thesis, v. 2010, n. 13, p. 15-25, 2010.

EFFGEN, E. M., DARDENGO, M. C. J. D., SILVA, P. A., PASSOS, R. R., \& EFFGEN, T. A. M.. Caracterização de atributos físicos de solos em área sob cultivo de sorgo no sul do 
Estado do Espírito Santo. X Encontro Latino Americano de Iniciação Científica e VI, São José dos Campos-SP, p. 2842-2845, 2006.

MELO, A. F. D.; SOUZA, C. M. M.; REGO, L. G. S.; LIMA, N. S.; MOURA, I. N. B. M. Pedogênese de chernossolos derivados de diferentes materiais de origem no oeste potiguar. Revista Agropecuária Científica no Semiárido. v.13, p. 229-235, 2017.

MOTA, J.C.A; FREIRE, A.G.; ASSIS JÚNIOR, R.N. Qualidade física de um Cambissolo sob sistemas de manejo. Revista Brasileira de Ciência do Solo. Vol. 37, pg. 1196, 2013.

RODRIGUES, C., OLIVEIRA, V. Á. D., SILVEIRA, P. M. D., \& SANTOS, G. G.Chemical dispersants and pre-treatments to determine clay in soils with different mineralogy. Revista Brasileira de Ciência do Solo, v. 35, n. 5, p. 1589-1596, 2011.

SANTOS, H. G., JACOMINE, P. K. T., DOS ANJOS, L. H. C., DE OLIVEIRA, V. A., LUMBRERAS, J. F., COELHO, M. R. \& CUNHA, T. Sistema brasileiro de classificação de solos. Brasília, DF: Embrapa, 2018.

TAVARES FILHO, J. BARBOSA, G. M. de C.; RIBON, A. A. Waterdispersible clay in soils treated with sewage sludge. Revista Brasileira de Ciência do solo, v.34, p.1527-1534, 2010.

TEIXEIRA, P. C.; DONAGEMMA G. K.; WENCESLAU, A. F.; TEIXEIRA, G. Manual de Métodos de Análise de Solo. 3. ed. Rio de Janeiro: Embrapa Solos, 573 p. 2017.

VAN LIER, Q. J. Física do solo. Viçosa, MG: Sociedade Brasileira de Ciência do Solo, 2010. 